\title{
A CIÊNCIA PÓS-MODERNA, OS INTELECTUAIS E O ENGAJAMENTO SOCIAL: APONTAMENTOS SOBRE A PRODUÇÃO ACADÊMICA DE AUTORIA SURDA
}

\author{
Maria Clara Maciel de Araújo Ribeiro*
}

\begin{abstract}
RESUMO
Este estudo reflete sobre um fazer acadêmico que se mostra mesclado a um fazer social, político e militante: o fazer acadêmico empreendido por sujeitos surdos na pós-graduação stricto-sensu. Compreendido como representante de um modelo de racionalidade científica emergente, tal fazer apresenta a particularidade de ser autorreferenciável e, em alguma medida, autobiográfico. A partir da focalização da tensão estabelecida entre o discurso acadêmico e o discurso ativista, este estudo lança luz sobre um fato social e acadêmico notadamente pós-moderno.

Palavras-chave: Surdos. Intelectuais. Discurso acadêmico. Ativismo social.

ABSTRACT

This study reflects on a kind of academic production that is mixed with social, political and militant action: the academic production undertaken by deaf individuals in stricto-sensu post-graduation courses. Being understood as representative of an emerging model of scientific rationality, this academic production has the distinctiveness of being selfreferenceable and, to some extent, autobiographical. Focusing on the tension established between academic and activist discourses, this study sheds light on a social and academic fact that is notably postmodern.
\end{abstract}

Keywords: Deaf. Intellectuals. Academic discourse. Social activism.

\footnotetext{
* Doutora em Estudos Linguísticos (linguística do texto e do discurso) pela Universidade Federal de Minas Gerais. Professora do Departamento de Comunicação e Letras da Universidade Estadual de Montes Claros.E-mail: mclaramaciel@hotmail.com
} 


\section{Introdução}

Apesarda falta de consenso dos estudiosos quantoao estabelecimento da pós-modernidade na ciência (ou até mesmo da existência dessa condição sociocultural), é inegável que nenhuma outra época experimentou tamanha fluidez e diversidade de interesses e manifestações acadêmico-científicas e culturais como a nossa. $\mathrm{O}$ fosso foi assustadoramente alargado e as hegemonias estão ameaçadas. A modernidade tornou-se líquida e os fazeres científicos e sociais podem agora se fundir.

Este estudo reflete sobre a condição pós-moderna que torna possível a inter-relação entre ciência e ativismo social. Se pensarmos que no paradigma de racionalidade científica dominante sujeito e objeto ocupam instâncias epistemológicas distintas e distantes, consideraremos como inovador o fato de ser possível produzir atualmente um conhecimento científico autorreferenciável e com certo grau de autobiografismo - o que caracterizaria tal empreendimento como representante autêntico de um modelo de racionalidade científica emergente, como classifica o sociólogo português Boaventura de Sousa Santos. Refiro-me à atual produção acadêmica empreendidada por surdos, onde ao fazer acadêmico-científico mescla-se um fazer político social, notadamente militante frente ao Movimento Surdo.

É diante dessas evidências que objetivo nesse estudo discutir como sujeitos surdos têm se tornado intelectuais específicos, produtores de uma cientificidade que questiona outra ao construir um conhecimento pautado na contra-argumentatividade, ou melhor, na refutação discursiva de um saber construído ao longo de séculos, sobretudo pela área da saúde. Ilustro a discussão com apontamentos sobre três teses de doutorado em Educação produzidas por surdos e aqui focalizadas a partir das proposições de Foucault (2005), Renato Ribeiro (2006), Boaventura Santos (2005), além de autores complementares.

\section{Um fazer acadêmico-científico}

Para começar, traço, primeiramente, o lugar teórico a partir do qual compreendo as teses de doutorado em Educação que ilustram a seguinte 
discussão. Uma definição despretensiosa e mais ou menos corrente poderia caracterizar o gênero tese como "um trabalho científico original, que apresenta uma reflexão aprofundada sobre um tema específico, nunca antes tratado e cujo resultado final constitui uma contribuição valiosa e única para o conhecimento da matéria tratada"1 (grifo meu). Detenho meu olhar, por um instante, sobre o valor de ciência reivindicado nessa definição.

A polêmica discursiva que se estabelece entre diferentes áreas do conhecimento, quanto à definição de "quem" produz valores científicos ou não é conhecida. Eco (1992, p. 20) adentra essa questão com a dicotomia tese científica vs tese política, no esforço de considerar o que é a cientificidade. Para ele, tal bipartição é provocativa e equivocada, pois faz supor que uma tese política não possa ser científica. Advogando contra tal posição, afirma que frequentemente "fala-se nas universidades em ciência, cientificismo, pesquisa científica, valor científico de um trabalho", de forma que tais termos acabam por fomentar "equívocos involuntários, seja por mistificação ou por suspeitas ilícitas de mumificação da cultura" (ECO, 1992, p. 20). Cabe, pois, definir de que cientifismo se fala nas universidades. Segundo o autor:

Para alguns, a ciência se identifica com as ciências naturais ou com a pesquisa em bases quantitativas: uma pesquisa não é científica se não se conduzir mediante fórmulas e diagramas. Sob este ponto de vista, portanto, não seria científica uma pesquisa a respeito da moral em Aristóteles; mas também não o seria um estudo sobre consciência de classe e levantes camponeses por ocasião da reforma protestante (ECO, 1992, p. 20).

Obviamente, não é esse o valor de "científico" que circula nas universidades. Abraçando essa causa, Eco (1992, p. 21-22) define a que título um trabalho merece chamar-se científico, em sentido lato. Para ele, um estudo é científico quando apresenta os seguintes requisitos: a) o estudo focaliza um objeto definido e reconhecível por todos; b) o estudo diz sobre

1 Definição apresentada pela Faculdade de Ciências Sociais e Humanas da Universidade Nova de Lisboa. Disponível em: <www2.fcsh.unl.pt/docentes/cceia/guias1.htm+o+que+é+ uma + tese $\% 3 F \& c d=2 \& h l=p t-B R \& c t=c l n k \& g l=b r>$. Acesso em: 05 mai. 2012. 
o objeto algo que ainda não foi dito ou revê sob ótica diferente o que já se disse; c) o estudo é útil aos demais; d) o estudo oferece elementos para a verificação e a constatação das hipóteses apresentadas ${ }^{2}$.

Elementos de cientificidade, portanto, podem aplicar-se a qualquer tipo de pesquisa, mesmos as ditas políticas ou engajadas. Aliás, com o inter-relacionamento, cada vez maior, entre pesquisa científica e pesquisa política, a distinção entre elas tem-se mostrado improcedente. Pode-se pensar que todo estudo acadêmico que contribua para o desenvolvimento do conhecimento geral terá um valor político positivo; afinal, por trás de todo fazer acadêmico se prevê uma necessidade operacional, prática ou teórica, isto é, interesses específicos governam os rumos da pesquisa científica. Porém, da mesma maneira, pode-se, como argumenta Eco, prever que uma pesquisa engajada, que se queira séria e respeitada, precisa seguir determinados princípios.

Assim, apesar de os princípios - itens de a) a d) - arrolados por Eco parecerem, à primeira vista, um tanto amplos, quando se dedica a explicálos um a um, o autor faz desaparecer essa impressão: para ele, se um estudo não mostrar rigor, organização e clareza de critérios, além de uma série de elementos que possibilitem a sua verificação ou contestação a posteriori, não pode chamar-se, por direito, científico.

Contudo, a definição de ciência corrente e hegemônica socialmente parece reservar critérios de cientificidade apenas para disciplinas específicas, naturais e/ou exatas, nas quais os valores do homem interferem pouco, como na matemática, física, química ou biologia. A imagem do cientista de jaleco branco, em um laboratório asséptico, é certamente a que mais tem respaldo no imaginário social. Apesar disso, vemos serem praticadas ciências humanas e serem formados cientistas sociais e políticos.

O conhecimento científico, já definiu Santos (2000), não é nem o único, nem o mais completo - e para Anísio Teixeira, tampouco é o mais complexo, pois, no seu entender, "como a medicina, a educação é uma arte. E arte é algo de muito mais complexo e de muito mais completo que uma ciência" (TEIXEIRA, 1997, p. 197).

2 Apesar da complexidade dessa discussão, ultrapassa o escopo do presente trabalho esmiuçar, em pormenores, os critérios de Eco (1992), a quem remeto o leitor interessado. 
Controvérsias à parte, o que importa aqui é definir que o valor de cientificidade requisitado neste estudo parte mais de "condições de cientificidade" proporcionadas pelos programas de pós-graduação do que da tradição formal que determina quem produz ou não "valores científicos". Parte também de uma definição de ciência pós-moderna, que rompe com a hegemonia, como veremos a seguir.

O que vemos, portanto, atualmente, é que cidadãos surdos - que já foram taxados de mudos, deficientes e incapazes - contribuem atualmente para a construção e expansão do conhecimento sobre si. Refiro-me a surdos intelectuais engajados, que se voltam para a academia para desmitificar visões estereotipadas do seu povo e até mesmo contestar o saber construído pelas Ciências da Saúde que, a rigor, veem nos surdos apenas uma patologia a ser tratada ou idealmente curada. São, portanto, responsáveis pela produção de uma cientificidade que inova tanto na seleção de temas de pesquisa, quanto na perspectiva de desenvolvimento, pois se trata de uma ótica interna que confere às temáticas tratamento emancipatório, na medida em que reorganiza a relação entre sujeito da pesquisa e objeto pesquisado (nessas pesquisas, levemente sobrepostos).

\section{Um fazer ativista: o caso dos surdos intelectuais}

Voltando ao subtítulo dessa seção, temos que a palavra "surdos" funciona como substantivo e "intelectuais", como adjetivo. Para receber o status de intelectuais, tanto na comunidade surda quanto fora dela, é necessário que tais sujeitos tenham algum envolvimento acadêmico - no mínimo graduação, seguida preferencialmente de títulos de pós-graduação - e uma considerável atividade social na luta, conscientização, discussão e promoção dos direitos do ser surdo. Mas, afinal, de maneira ampla, vale perguntar: o que é ser intelectual?

Ribeiro (2006, p. 137) postula que o cientista específico às ciências humanas é o intelectual, figura que se distingue do cientista das ciências exatas ou naturais na medida em que esse lida com coisas, enquanto aquele lida com objetos que falam por si mesmos, o que "introduz um elemento irredutível de imprevisão e indeterminação no conhecimento". Veem-se aí duas formas de ciência que, na opinião do autor, não se relacionam à 
tradicional oposição entre ciência hard e soft, mas a duas diferenças fundamentais: a primeira indica que o sujeito, nas ciências humanas, está mais próximo de seu objeto (que será também humano ou derivado dele), de forma que esse indício de mescla "torna-se o problema principal a assegurar sua certeza (...)" (p. 138).

A segunda relaciona-se à aplicação prática do conhecimento em cada polo: nas ciências das coisas tal aplicação prioriza a tecnologia, enquanto nas ciências dos homens ela se volta para a formação de um público, isto é, para a formação de uma consciência, insurgida por dado conhecimento, como fim último. Por exemplo, indo além das ciências humanas, podemos pensar que se formou público para o discurso de Freud sobre a sexualidade infantil, o que acabou por relativizar o legado deixado por Rousseau, que considerava as crianças como seres puros e não mundanos. Da mesma forma, a sociologia mostrou que a violência não advém da maldade humana, mas principalmente de condicionamentos sociais - e o público formado, nesse caso, ultrapassa o limite dos muros da academia.

Para apurar a sua noção de intelectual, Ribeiro (2006, p. 141) sustenta ainda que "é ele quem lida com a ágora ${ }^{3}$, com o dar caráter público àquilo cujo conhecimento estaria, num primeiro momento, fechado no ambiente acadêmico". O intelectual se caracteriza, assim, pelo "uso público do conhecimento", pela capacidade de conversão de um estudo inicialmente voltado apenas para o avanço interno do conhecimento em algo a ser apropriado socialmente. Enquanto o cientista conhece, o intelectual avalia o mérito do conhecimento.

Ao discutir o uso e a apropriação do conhecimento, o intelectual se torna, assim, o político da ciência. No entanto, no entender do autor, nada impede "que haja cientistas do social e intelectuais das ciências biológicas" (RIBEIRO, 2006, p. 144). Vê-se, pois, que Ribeiro (2006) não distingue o intelectual do cientista unicamente por seus objetos, mas, sim, por suas atitudes, donde se conclui que a diferença fundamental entre o chamado cientista e o chamado intelectual é o uso social do conhecimento, aqui entendido como um tipo de engajamento político.

3 Segundo o dicionário Michaelis on-line (2011): "praça pública onde os gregos celebravam as suas assembleias e aplicavam a justiça". 
Ao distinguir o intelectual universal (representante de uma consciência coletiva voltada para as questões das massas) do intelectual específico (que se constrói e se sustenta como membro de um grupo específico, para o qual volta sua atenção), Foucault (2004, p. 13) adverte que "é preciso pensar os problemas políticos dos intelectuais não em termos de 'ciência/ideologia', mas em termos de "verdade/poder'".

Ora, o intelectual específico se levanta, em geral, contra um sistema de poder hegemonicamente constituído e questiona um regime de verdade, ao mesmo tempo em que busca instituir outro. E, se o faz em nome próprio, é porque representa certa coletividade, um público específico: "quem fala e age? Sempre uma multiplicidade, mesmo que seja na pessoa que fala ou age. Nós somos todos pequenos grupos. Não existe mais representação, só existe ação: ação de teoria, ação de prática em relações de revezamento ou em rede", nos diz Deleuze, em conversa com Foucault (2004, p. 70).

Especificamente sobre surdos intelectuais, assim se pronunciam Rezende e Rezende Jr. (2007, p. 196):

[...] os surdos intelectuais específicos não exigem dos outros o que eles devem fazer, não impõem sua vontade política sobre os outros, não infligem a sua produção da verdade como sendo a única, excluindo as outras possibilidades, as outras verdades. O seu papel é analisar os seus espaços, os seus acontecimentos, os seus balizamentos, abanando e agitando outros pensares, os outros fazeres, dissipando os velhos conceitos, para uma reproblematização de outras vontades políticas e produções da verdade, enfim para o eclodir de novos conceitos condizentes com o ser surdo com suas peculiaridades plenas. Mais do que isso, que sejam esparzidos pelos seios sociais por meio de ensinamentos advindos dos surdos intelectuais específicos.

Os autores acima defendem a superioridade do intelectualpesquisador surdo em face dos não surdos na abordagem de problemas que envolvem povos sinalizadores. Para a autoria surda supracitada, intelectuais surdos não exigem, impõem ou infligem a produção de verdades de outrem (como os ouvintes costumam fazer com eles, subentende-se), mas atuam em um espaço próprio e produzem um autoconhecimento deslocado da lógica dominante (a visão dos ouvintes sobre os surdos). Não se pode perder de 
vista, contudo, que surdos intelectuais estão enredados na mesma trama de poder que combatem, isto é, deixar de ser dominado, parece implicar, em alguma medida, exercer algum domínio.

\section{Um indício de mescla}

É assim que, aos poucos, intelectuais advindos de grupos sociais discriminados tornam-se pesquisadores e comprometem-se com seus setores de origem, desencadeando a produção de um conhecimento voltado para a promoção imediata de seu grupo cultural. Isso implica falar de atividades acadêmicas articuladas "por" sujeitos surdos que, "ao desenvolverem suas pesquisas, privilegiam a parceria 'com' os movimentos sociais e extrapolam a tendência ainda hegemônica no campo das ciências humanas e sociais de produzir conhecimento 'sobre' os movimentos e os seus sujeitos" (GOMES, 2010, p. 494, grifos meus).

Na visão de Gomes (2010), é provável que o campo da educação seja a área do conhecimento em que a inserção de intelectuais específicos (negros, homossexuais, surdos, feministas...) se faça mais presente e visível. Como é de se esperar - e como informa a autora -, esses sujeitos

[...] se configuram não só como pesquisadores que atuam no meio acadêmico. Eles produzem conhecimento e localizam-se no campo científico. São intelectuais, mas um outro tipo de intelectual, pois produzem um conhecimento que tem como objetivo dar visibilidade a subjetividades, desigualdades, silenciamentos e omissões em relação a determinados grupos [...] e suas vivências. Para tal, configuram-se como um coletivo, organizam-se e criam associações científicas a fim de mapear, problematizar, analisar e produzir conhecimento (GOMES, 2010, p. 495).

É aí que se enquadram os surdos intelectuais. E eles não são os únicos. A autora citada, por exemplo, trata especificamente da atividade acadêmica de negros intelectuais, embora a reflexão que tece sirva, bem amplamente, para o caso dos surdos, uma vez que o que se discute aqui é a produção de conhecimento politicamente (auto) posicionado. A autora 
inspira-nos ainda a pensar que, ao tematizarem questões surdas na academia, tais sujeitos "produzem um tipo de conhecimento não mais pautado no olhar do outro", ouvinte eventualmente comprometido com o percurso de lutas do povo surdo, "mas pelo olhar crítico e analítico" do próprio surdo como pesquisador da temática surda. Rezende e Rezende Jr. (2007), por exemplo, destacam essa vantagem na citação anterior. Assim, não se trata mais de um olhar dito neutro e distante sobre fenômenos sociolinguísticos e educacionais que envolvam surdos, mas sim de uma análise e uma leitura crítica de quem vivencia tais conflitos na sua trajetória de vida tanto pessoal quanto coletiva, inclusive no meio acadêmico-profissional.

É claro que "equilibrar-se no fio da navalha" traz múltiplas tensões. Apesar de certamente enriquecer e renovar as visões até então apresentadas, o surdo intelectual "ameaça territórios historicamente demarcados dentro do campo das ciências sociais e humanas, traz elementos novos de análise e novas disputas aos espaços de poder acadêmico", além de ser colocado sob suspeita por aqueles que só acreditam na produção de conhecimento neutro e deslocado dos sujeitos que o produzem (GOMES, 2010, p. 492).

Foucault (2006) sugere que todo percurso de luta contra formas de opressão é, de alguma forma, tributário do percurso de lutas operárias, iniciado no século XVIII. Assim, ao lutarem contra formas de coação e de controle sobre si, mulheres, negros, surdos e homossexuais se mostram ideologicamente afinados com o proletariado, uma vez que "se o poder se exerce como ele se exerce, é, na verdade, para manter a exploração capitalista" (FOUCAULT, 2006, p. 46). Corroborando essa visão, Lane (2002) discute que a origem da noção de deficiência remonta ao século XVIII, quando foi preciso separar os considerados sadios (aptos ao trabalho) dos deficientes (inaptos e onerosos ao governo). Em outras palavras: os movimentos sociais das minorias estão, de alguma forma, sim, ligados à ideologia do movimento operário, uma vez que buscam combater formas de controle conduzidas por toda parte pelo mesmo sistema de poder.

Nesse sentido, pensando na intelectualidade negra na academia, Mama (2010, p. 605) relata o descaso da comunidade científica mundial quanto às publicações africanas sobre os efeitos nocivos da globalização. Deve-se a estudiosos africanos algumas das mais fortes críticas à globalização 
e ao imperialismo. Tais críticas, no entanto, são reduzidas no máximo à categoria fútil de "literatura de protesto", pois são completamente ignoradas pelas principais obras editadas pelo mundo sobre a temática. Para a autora, os intelectuais negros (africanos) produzem uma pesquisa acadêmica que vê a si própria como "parte integrante da luta pela liberdade e que responde, não perante esta ou aquela instituição, regime, classe ou gênero, mas perante a imaginação, as aspirações e os interesses da gente comum" (MAMA, 2010, p. 603). Ora, Foucault já disse que o sistema de controle e poder capitalista se reconduz de distintas maneiras em distintos lugares.

Mama (2010, p. 605) nos faz pensar que uma atitude responsável e ativa exige que façamos mais do que nos colocarmos à margem dos problemas sociais. Exige que, enquanto pesquisadores, "ultrapassemos a nossa tradição liberal de neutralidade perante as políticas e que desenvolvamos uma ética mais radical, susceptível de questionar e interpelar ativamente as hegemonias globais". A autora se (nos) questiona:

Qual o contributo que a nossa pesquisa e o nosso conhecimento poderá [sic] trazer aos diversos contextos dos povos que estudamos? Como é que nossas atividades de pesquisa afetam a vida daqueles que estudamos? Será possível desenvolvermos estudos sobre África de maneira a estes mostrarem um maior respeito para com as vidas e as lutas do povo africano e as suas agendas? Será possível promovermos estudos que contribuam para o bem da África? (MAMA, 2010, p. 610).

A contribuição social da pesquisa realizada por surdos não pode ser mais clara: primeiramente, como agenda geral, tem a função de ressemantizar o conceito de surdez, politizando e ressignificando a discussão a partir da suplantação da ideia de deficiência. Nas três teses selecionadas para reflexão nesta presente pesquisa esse propósito se mostra bastante claro e presente. O quadro abaixo expõe as teses selecionadas. 


\section{Caracterização da Tese 1}

Título: Implante coclear na constituição dos sujeitos surdos

Autor: Patrícia Luiza Ferreira Rezende

Instituição: Universidade Federal de Santa Catarina

Programa: Programa de Pós-Graduação em Educação

Linha: Sem indicação

Orientadora: Profa. Dra. Ronice Muller de Quadros

Co-orientadora: Profa. Dra. Maura C. Lopes

Ano de defesa: 2010

Número de páginas: 164

Objetivo: Problematizar os discursos sobre o implante coclear, produzidos pelas famílias e profissionais da saúde, investigando como tais discursos constituem os surdos.

Corpus: entrevistas com mães (líderes sociais) de crianças implantadas, material midiático e material de eventos sobre o implante coclear.

\section{Caracterização da Tese 2}

Título: Surdos: vestígios culturais não registrados na história

Autora: Karin Lílian Strobel

Instituição: Universidade Federal Santa Catarina

Programa: Programa de Pós-Graduação em Educação

Linha: Educação e processos inclusivos

Orientadora: Prof. Dra. Ronice Muller de Quadros

Co-orientadora: Profa. Dra. Gladis Perlin

Ano de defesa: 2008

Número de páginas: 176

Objetivo: Documentar aspectos culturais que constituem a história do povo surdo não sistematizada em publicações registradas, relacionando os fatos históricos das instituições escolares com os do povo surdo organizado politicamente.

Corpus: narrativas de seis ex-alunos surdos, entre 50 e 60 anos, oriundos da mesma escola, versando sobre a memória escolar de cada um.

\section{Caracterização da Tese 03}

Título: A experiência e a pedagogia que nós surdos queremos

Autor: Wilson Oliveira Miranda

Instituição: Universidade Federal do Rio Grande do Sul

Programa: Programa de Pós-Graduação em Educação

Linha: Sem indicação

Orientador: Prof. Dr. Carlos Bernardo Skliar

Ano de defesa: 2007

Número de páginas: 152

Objetivo: Pesquisar a pedagogia surda constante nos discursos surdos, atentando para as diferenças entre a pedagogia surda e a dita ouvinte.

Corpus: Entrevistas realizadas com educadores surdos sobre a pedagogia surda que almejam um dia implementar. 
Vemos, a tese 1 (T1) enfrentar o império do Implante Coclear ${ }^{4}$ com o objetivo de fazer frear a voracidade dos discursos sobre sua introdução na vida dos surdos ou, pelo menos, com o objetivo de fazer a Libras sobreviver (ou entrar) nos espaços já dominados por ele. Mostra como mães têm se tornado agentes de saúde de seus filhos, no afã de tratar aquilo que, para a autora, não é uma doença, mas apenas outra forma de estar no mundo.

A tese 2 (T2), por sua vez, denuncia histórias de horrores (maus tratos e abusos) vivenciadas por surdos numa época em que esses ainda estavam fortemente subjugados ao domínio de instituições ouvintistas. Dirige-se sobretudo ao povo surdo, interlocutor modelo da tese, no intuito de alertá-lo sobre a precariedade do passado e incitá-lo a reescrever, com atitudes outras, o futuro.

Já a tese 3 (T3) objetiva fazerem ouvidas as intervenções pedagógicas esperadas e produzidas pelos próprios surdos sobre a sua educação. Dá voz a pedagogos surdos e propõe a educação que "nós surdos queremos", produzida por surdos e para surdos.

A mudança social está na pauta das pesquisas produzidas por surdos e apresentadas aqui. $\mathrm{O}$ que parece estar em causa na pesquisa de base ativista, portanto, é a possibilidade de melhoria social para o grupo ou organização comunitária da qual é representante.

Mas é possível perguntar: por que só muito recentemente surdos começaram a frequentar a universidade? Em nosso país, foi necessário sancionar em 2002 a lei 10.436 (homologada, em 2005, pelo decreto 5.626), reconhecendo a Libras como meio legal de comunicação do surdo brasileiro, para que surdos sinalizadores começassem a ser aceitos com a "exoticidade" de sua língua. Antes disso, apesar de todos os avanços e pesquisas relativas à Língua Brasileira de Sinais e à educação de surdos, o que se observava era a pouquíssima crença ou atenção conferida às pessoas surdas. Após a homologação da lei, contudo, a discussão sobre o povo surdo (sua língua, cultura e educação) cresceu e, junto com ela, o número de vagas nas escolas, não apenas para surdos, mas também para intérpretes de Libras, em decorrência das políticas públicas de inclusão que garantem,

4 O implante Coclear é uma tecnologia (um implante interno) que promete reverter a surdez. 
por exemplo, a presença de intérprete em concursos públicos, ainda que essa norma não seja totalmente cumprida nas/pelas instituições.

O gráfico a seguir, extraído de Vilhalva (2010, p. 02), ilustra a aprovação de surdos em programas de pós-graduação antes e após a publicação da referida lei. Antes da lei, o percentual era insignificante. Nos anos posteriores ao decreto (de 2005 a 2010), constata-se um crescimento significativo e, em 2010, um salto surpreendente, pois o número de surdos na pós-graduação representa mais da metade do acumulado entre 2005 e 2010, fato que não deixa dúvidas quanto ao ingresso, cada vez maior, de surdos na pós-graduação stricto sensu:

\section{Gráfico 01}

\section{Surdos Aprovados em Pós - Graduação - Mestrado e Doutorado no Brasil depois da Lei 10436/2002 e do Decreto 5626/2005}

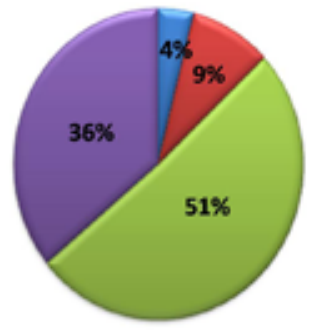

II) 199022000

a 2000 a 2005

a 200532010

w2010

É possível afirmar que a maioria dos surdos inscritos em programas de pós-graduação, atualmente no Brasil, realizam pesquisas com algum grau de engajamento sociocomunitário. Talvez não seja exagero afirmar que esse número se torna totalitário se pensarmos no universo de surdos usuários de Libras matriculados em programas de pós-graduação em educação.

Sou inclinada a pensar que a entrada de surdos na pós-graduação stricto-sensu e o desenvolvimento pesquisas (auto)engajadas é um fenômeno pós-moderno. Seria impossível, por exemplo, deslocar o quadro atual e tentar imaginá-lo há três décadas. Em primeiro lugar, surdos seriam considerados inaptos ao grau de instrução unicamente pela falta de audição 
(fruto da visão limitada sobre os surdos que ainda caracterizava a época). Em segundo lugar, pesquisas tão claramente engajadas, onde sujeito e objeto de pesquisa podem se sobrepor, poderiam ser consideradas insultos à lógica acadêmico-científica dominante, e jamais poderiam prosperar.

Atualmente, todavia, doutorandos surdos são reconhecidos como produtores de um conhecimento singular que tem expandido em distintas perspectivas o conhecimento sobre o povo surdo. Trata-se, sim, da produção de uma cientificidade. Apesar de óbvia para alguns, essa afirmação se direciona especificamente àqueles que questionam o teor de cientificidade (leia-se "verdade") de teses ditas engajadas, ou melhor, no caso em questão, de pesquisas conduzidas por surdos sobre temáticas que giram em torno da surdez. Ora, quem foi que proclamou a disjunção da ciência com a realidade social ou com a consciência coletiva?

A esses, e a todos nós, envolvidos em atividades acadêmicas, apresento o olhar do sociólogo português Boaventura de Sousa Santos, para quem "a realidade parece ter tomado definitivamente a dianteira sobre a teoria" (SANTOS, 2000, p. 18). Defendendo um fazer científico pós-moderno, ao mesmo tempo integrado e fragmentado, "de bem" com a realidade empírica e com o senso comum, Santos (2005) afirma que a ordem científica dominante, herdada do século XVI e consolidada no século XIX, que apresenta o que ele chama de paradigma dominante do fazer científico, está em crise e que um novo paradigma começa a revelar-se, a saber, o paradigma emergente. O primeiro é assim caracterizado pelo autor:

Pode falar-se de um modelo global de racionalidade científica que admite variedade interna, mas que se distingue e defende, por via de fronteiras ostensivas e ostensivamente policiadas, duas formas de conhecimento não científico (e, portanto, irracional) potencialmente perturbadoras e intrusas: o senso comum e as chamadas humanidades ou estudos humanísticos (em que se incluíram, entre outros, os estudos históricos, filológicos, jurídicos, literários, filosóficos e teológicos) (SANTOS, 2005, p. 20).

Pensando como Eco (1992), Santos (2005, p. 22) postula que, no paradigma dominante, a matemática ocupa um lugar central, o que gera pelo menos duas consequências principais: 1) conhecer torna-se sinônimo 
de quantificar, de forma que o rigor científico acaba por ser aferido por meio do rigor das medições. Por essa via, o que não é quantificável, tornase cientificamente irrelevante. É assim que as qualidades intrínsecas ao objeto acabam sendo desqualificadas "e em seu lugar passa a imperar as quantidades em que eventualmente se podem traduzir"; 2) a redução da complexidade é considerada condição do método científico. Em adição, conhecer significa também dividir e classificar implica desmontar o que é complexo e submetê-lo a leis seguras e objetivas.

O modelo de racionalidade científica que está na base do paradigma dominante, contudo, segundo o autor, mostra-se em crise após o advento de uma série de condições teóricas inovadoras, advindas tanto da física e da biologia quanto do fortalecimento de diversas áreas das chamadas Humanidades. Para Santos (2000, p. 11), vivemos um período de transição de racionalidades entre o paradigma da ciência moderna e um novo paradigma, cuja emergência aponta para a construção de uma ciência chamada por ele pós-moderna 5 .

No paradigma emergente, o conhecimento se faz prudente, mas visa a uma vida decente. Em outras palavras, para Santos (2005, p. 60), um paradigma outro não pode mais apresentar-se apenas como "um paradigma científico (um paradigma prudente), tem de ser também um paradigma social (o paradigma de uma vida decente)". Portanto, o homem e a realidade social, que haviam sido expulsos do paradigma dominante, entram agora pela porta da frente nesse "novo" modelo de racionalidade científica.

Para Santos (2005, p. 80), "todo conhecimento é autoconhecimento". Para ele, apesar de a racionalidade científica, hegemônica na ciência moderna, ter consagrado o homem como sujeito epistêmico, ela o

\footnotetext{
5 De acordo com Gonçalves (2011), o amplo e multifacetado movimento sociocultural da pós-modernidade ganha força aproximadamente no último quarto do século XX. A noção, de cunho estético ou histórico, é bastante fluida e tenta caracterizar uma época em que as expressões (artísticas e científicas) são dominadas pela lógica cultural do capitalismo tardio, pelo fim das metanarrativas e por uma cultura instalada pelo pós-guerra e pela visão pós-industrial. Boaventura Santos utiliza-se do termo para falar precisamente da fase de transição paradigmática em que nos encontramos, caracterizada pela extensão ou transformação da ciência preexistente (moderna) em uma nova (pós-moderna), ainda com perfil não estabilizado.
} 
expulsa enquanto sujeito empírico, uma vez que "um conhecimento objetivo, factual e rigoroso não toleraria a interferência dos valores humanos" (SANTOS, 2005, p. 80). A partir dessa visão, sujeito e objeto passaram a encarnar sujeitos epistemológicos distintos e distantes $^{6}$. Hoje, no entanto, discute-se a importância de se considerar o objeto como a continuação do sujeito por outros meios, de forma a se considerar o conhecimento advindo dele como uma espécie de autoconhecimento, o que imputaria à ciência um caráter quase autobiográfico:

Hoje sabemos ou suspeitamos que as nossas trajetórias de vida pessoais e coletivas (enquanto comunidades científicas) e os valores, as crenças, os prejuízos que transportam são a prova íntima do nosso conhecimento, sem o qual as nossas investigações laboratoriais ou de arquivo, os nossos cálculos ou os nossos trabalhos de campo constituiriam um emaranhado de diligências absurdas sem fio nem pavio. No entanto, este saber, suspeitado ou insuspeitado, corre hoje subterraneamente, clandestinamente, nos não-ditos de nossos trabalhos científicos (SANTOS, 2005, p. 85).

Na ciência dita pós-moderna, segundo o paradigma emergente, o caráter autorreferenciável já não é mais dissimulado, mas assumido. A partir de uma ressubjetivação, o conhecimento é visto como correlato a um saber prático de vida. Ora, é isso justamente o que se apresenta no corpus desta pesquisa: o conhecimento construído e veiculado apresentase ao sujeito pesquisador como a formulação de um autoconhecimento, de um saber que também o referencia. Falar do outro (surdo) é falar de si; demonstrar seus anseios e sentimentos em relação à comunidade surda é tocar os sentimentos e anseios do outro. Tocar a ferida alheia é também tocar a sua própria ferida.

\footnotetext{
$6 \mathrm{Na}$ antropologia, por exemplo, "a distância empírica entre o sujeito e o objeto era enorme. O sujeito era o antropólogo, o europeu civilizado, o objeto era o povo primitivo ou selvagem. Nesse caso, a distinção sujeito/objeto aceitou ou mesmo exigiu que a distância fosse relativamente encurtada através do uso de metodologias que obrigavam a uma maior intimidade com o objeto, ou seja, o trabalho de campo etnográfico, a observação participante" (SANTOS, 2005, p. 80-81).
} 
Enfim, para Santos (2000), o paradigma emergente elege a comunidade, a participação e a solidariedade como princípios. Sua racionalidade torna-se, assim, estético-expressiva, e o conhecimento ora regulatório constrói um conhecimento emancipatório que se mostra responsável (ético) e político (participativo).

O autor admite que a reflexão epistemológica tecida por ele está muito mais avançada e sofisticada do que a prática científica ainda vigente: no seu entender, nenhum de nós (inclusive ele próprio) pode ainda visualizála e praticá-la com clareza, pois vivemos um momento de transição de racionalidades. Deve-se considerar, no entanto, que, contando da primeira publicação da obra (Um discurso sobre as ciências, 1987) até os dias de hoje, já se passaram 25 anos, de forma que, se por um lado, o paradigma chamado emergente mostrou, com mais nitidez, as suas feições, por outro, parece-me que ele não se mostrou inteiramente como se pensou, apesar de certamente conter traços da primeira projeção. O momento de transição (iniciado no pós-guerra) ainda perdura, apesar de certamente ter avançado em relação ao tempo de escrita da primeira versão da obra.

De minha parte, suponho que a pesquisa engendrada por pesquisadores surdos encaixa-se, com justeza, no paradigma emergente proposto por Santos (2005). Ora, trata-se de pesquisas científicas que, ao mesmo tempo em que reivindicam para si um lugar nas práticas acadêmicas correntes, constroem sobre elas um lugar político e identitário singularizado, que tanto parte de - quanto chega a - um meio social específico.

Adauto Novaes $(2006$, p. 7) na organização da obra $O$ silêncio dos intelectuais, questiona o que houve com os intelectuais (universais), antes tão ativos e agora tão silenciosos. Ele afirma que parece haver "uma dificuldade em representar o mundo atual", o que nos conduz a tempos de silêncio e reflexão. Marilena Chaú (2006, p. 30), em artigo na mesma obra, considera, no entanto, que o silêncio ou retraimento do engajamento dos intelectuais apenas é o sintoma de uma ausência mais profunda: "a ausência de um pensamento capaz de desvendar e interpretar as contradições que movem o presente", de maneira que "não se trata de uma recusa a proferir um discurso público, e sim da impossibilidade de formulá-lo". 
Talvez vivamos em uma época cujo intelectual universal seja minoria em meio à projeção de intelectuais específicos, ideólogos voltados para causas previamente definidas, como fruto do fortalecimento da democracia, economia e educação do país.

Neste momento, em que os intelectuais universais parecem mais silenciosos do que nunca, vemos a multiplicação de intelectuais específicos e a assunção de valores e defesas específicas daqueles uma vez chamados por Foucault de intelectuais universais. Nunca se viu, por exemplo, tamanha defesa dos direitos das minorias. Nesse ínterim, surdos intelectuais se fazem audíveis a partir da produção de discursos acadêmicos. Discursos acadêmicos em interface com discursos ativistas pró Movimento Surdo. Indícios de que o paradigma emergente de que nos fala Sousa (2005) tem começado a definir a sua face.

\section{Referências}

ECO, Humberto. Como se faz uma tese. São Paulo: Perspectiva, 1992. FOUCAULT, M. Microfisica do poder. Rio de Janeiro: Graal, 2004 GOMES, N. Intelectuais negros e a produção de conhecimento: algumas reflexões sobre a realidade brasileira. In: SANTOS, B. S.; MENEZES, M. P. (Org.). Epistemologias do Sul. São Paulo: Cortez, 2010. p. 492-518.

GONÇALVES, M. B. Boaventura de Sousa Santos e a Pós-Modernidade de Contestação: algumas notações marxistas. AURORA, ano V, n. 8, p. 1-17. Disponível em: <http://www2.marilia.unesp.br/revistas/index.php/ aurora/article/view/1265/1125>. Acesso em: 19 out. 2012.

LANE, H. L. Do deaf people have a disability? Sign Language Studies, Washington, v. 2, n. 4, p. 356-378, 2002.

MAMA, Amina. Será ético estudar a África? Considerações preliminares sobre pesquisa acadêmica e liberdade. In: SANTOS, B. S. MENEZES, M. P. (Org.). Epistemologias do Sul. São Paulo: Cortez, 2010. p. 603-637.

REZENDE, P. L. F.; REZENDE JR, F. F. Os surdos nos rastros da sua intelectualidade específica. In: QUADROS, R. M.; PERLIN, G. (Org.). Estudos Surdos. 1. ed. Petrópolis, RJ: Arara Azul, 2007. v. II, p. 190-211. 
Disponível em: $<$ http://editora-arara-azul.com.br/ParteB.pdf $>$. Acesso em: 12 mar. 2010.

RIBEIRO, R. J. O cientista e o intelectual. In: NOVAES, A. (Org.). $O$ silêncio dos intelectuais. São Paulo: Companhia das Letras, 2006. p. 137150.

SANTOS, B. de S. Introdução a uma ciência pós-moderna. 3. ed. Rio de Janeiro: Graal, 2000.

SANTOS, B. S. Um discurso sobre as ciências. 13. ed. Porto: Afrontamento, 2005.

TEIXEIRA, A. S. Educação e o mundo moderno. 2. ed. São Paulo: Cia. Editora Nacional, 1974.

VILHALVA, S. Trajetória política dos surdos no Brasil: aprovação em concursos públicos e pós-graduação: Mestrado e Doutorado antes e depois da Lei 1.0436/2002 e do Decreto 5.626/2005. In: CONGRESSO INTERNACIONAL DO INSTITUTO NACIONAL DE EDUCAÇÃO DE SURDOS, 11.; SEMINÁRIO NACIONAL DO INSTITUTO NACIONAL DE EDUCAÇÃO DE SURDOS, 17. 2010. Rio de Janeiro. Anais do Congresso. Edição: Instituto Nacional de educação de Surdos, 2010. Disponível em: <www.ines.gov.br/cienciaetecnologia/arquivos/anais2010. pdf $>$. Acesso em: 12 ago. 2012.

Data de registro: 25/04/2013

Data de aceite: $20 / 11 / 2013$ 